\title{
Study on the Effectiveness Evaluation of the Knowledge Structured Teaching Program of Family Planning Methods in the Men in the Rural Communities of Lucknow
}

\author{
Adaws Bthityi \\ Community Health Nursing, College of Nursing, King George'sMedical University, Lucknow U. P., India \\ adityakgmu89@gmail.com
}

\begin{abstract}
Family planning was constantly thought to be a lady's privilege. However, the truth of the matter is that all kinds of people are similarly answerable for planning and directing the family size. Henceforth investigating the role of men in family planning is especially significant, The goal of the review was to work on the information on family planning strategies among men and evaluate the adequacy of organized showing program on information on family planning techniques among men. Semi trial, non - randomized benchmark group configuration was utilized in provincial region in Sarorijini Nagar, Lucknow with 140 subjects (70 in each exploratory and control bunch). Purposive inspecting procedure was utilized. The devices utilized were segment variable and information poll with respect to information on family arranging strategies. In the benchmark group greatest subjects $87.1 \%$ had helpless information (mean score 12) and in the exploratory gathering greater part of subjects $65.7 \%$ had helpless information score (mean score 14.43) and no subject had great information score. After execution of the organized showing program in the trial bunch the critical improvement in the knowledge score had seen $61.4 \%$ in great information score. Discovering shows that in the benchmark group there was less distinction among pre and post - test information score (chi square worth 0.86, p esteem 0.353). In the test bunch there was extremely enormous contrast among pre and post - test information score (chi square worth 86.2, $p$ esteem $<0.001)$ and there were critical relationship of pre - test information score with the age, training, mate schooling, occupation, kind of family, month to month pay, wellspring of information, length of marriage was found.
\end{abstract}

Keywords: Structured teaching programme, family planning methods, effectiveness, rural area

\section{Introduction}

India is the second most populated country on the planet with almost a fifth of the total populace. As indicated by the 2017 amendment of the World Population Prospects, the populace remained at $1,324,171,354$.

During 1975-2019 the populace multiplied to 1.2 billion. The Indian populace arrived at the billion imprint in 1998. India is projected to be the world's most crowded country by 2024, surpassing the number of inhabitants in China. It is relied upon to turn into the main political element in history to be home to more than 1.5 billion individuals by 2030 , and its populace is set to arrive at 1.7 billion by 2050 . India has over half of its populace underneath the age of 25 and over $65 \%$ beneath the age of 35 . Reception of family arranging strategy is perhaps the best answer for tackle this issue. A quick populace development is a weight on the assets of many agricultural nations like India ${ }^{1}$. At present, India is the second most crowded country on the planet, contributing around $20 \%$ of births worldwide ${ }^{2}$. Unregulated richness, can think twice about monetary turn of events and political steadiness of a country. Numerous global foundations and associations have firmly pushed family making arrangements for controlling the unregulated births. Despite the fact that many investigations have been directed in this field, the segment research has zeroed in on the determinants of contraception utilized by women ${ }^{3}$.

In spite of India being the principal nation to dispatch a National Family Planning Program in 1952, there are as yet
$13 \%$ of wedded ladies with neglected necessities as to family arranging (NFHS III). Family arranging was constantly thought to be a lady's right, particularly in a male predominant society like India and the majority of the investigations on family arranging in emerging nations have since a long time ago centered around ladies as the subject of revenue. Very little work in this space has zeroed in on men. Yet, the truth of the matter is that all kinds of people are similarly answerable for arranging and controlling the family size. It is presently progressively perceived that the activities needed to accomplish enhancements in family arranging ought to likewise energize the dynamic cooperation of men, consequently investigating the job of spouse's preventative practices is especially important ${ }^{4}$. Male association additionally incorporates the quantity of men who empower and support their accomplice and friends to utilize family arranging and who impact the arrangement climate to be more helpful for creating male - related programs.

A little family is an ideal family, where each part can be cheerful, even the center pay is ideal for them. The little family can change in all condition. It is awesome and cheerful family as look at the enormous family. So for the prosperity of the family just as for the general public and country the little family standard ought to be keep, and a man assumes predominant part in this cycle. However, one of the main issue that non - industrial nations like India are confronting today is uncontrolled development of populace. Study the elements of prophylactic use, to comprehend current preventative use, inclination and issues of various 
techniques just as their goal to utilize prophylactic strategies later on.

A fast populace development is a weight on the assets of many agricultural nations like India. Right now, India is the second most crowded country on the planet, contributing around $20 \%$ of births around the world. Unregulated ripeness, can think twice about financial turn of events and political strength of a country. The male inclusion incorporates male contraception as well as the wide range of various public program exercises which pursues expanding the mindfulness, agreeableness and predominance of family arranging strategies among the guys. The use of present day strategies for contraception offer many benefits to the wellbeing and economy of both the couple and the country. The essential point of family arranging empowers ladies and men to design their families and space their youngsters using present day contraceptives. Notwithstanding, family arranging likewise accepts exercises like fruitlessness, hereditary guiding, contraception, early termination and disinfection. Of late, with an expanding mindfulness about HIV/AIDS, there has been an ascent in condom advancement and use which thusly prompts family arranging. This use thus is affected by the mindfulness and perspectives of individuals of regenerative age bunch and specifically the male accomplices.

Studies during the beyond couple of many years have set up a nearby and critical connection between the preventative use and fruitfulness inclinations. Thought about the social components in fruitfulness, as there is proof that the ripeness conduct changes with various social settings. The monetary worth credited to youngsters improves fruitfulness among the people who are financially poor. Anyway next to a few social variables, non accessibility and absence of information, mentality towards wanted family size, customary convictions and practices assume a significant part in family planning.7

One of fundamental goal of the Family Planning Program is to spread information on family arranging technique and create among individuals demeanor good for reception of family arranging strategies. The advancement accomplished in this circle is regularly by information, mentality and practice review. A Study was directed to survey the information, demeanor, and utilization of contraception in Andhra Pradesh. Information was gathered from 252 Auto drivers from 9 Auto Stand.81\% where having the information on various prophylactic strategies.59 \% didn't have positive mentality towards family arranging. The significant reasons were dread of tasks/incidental effects (46\%), burden of the accessible techniques (22\%) and need to have more children. 8

The control of fruitfulness and utilization of family arranging are of essential significance for an emerging nation like India. Since male are the prevailing leaders in India, ladies stay as the most under - served fragment. The establishment of marriage characterizes and outlines the existence of a lady as spouse, a mother and a house - creator. The utilization of contraceptives is constantly viewed as creatures spouse's obligation however it is of husband liability chiefly. Righeimer detailed that, all around the world men have not shared similarly with ladies the obligation of fruitfulness guideline. While family arranging endeavors have been coordinated only towards ladies, the absence of male association likewise mirrors the restricted choices accessible for women. 9

A large portion of the examinations on family arranging in non - industrial nations have since a long time ago centered around ladies as the subject of interest. Very little work in this space has zeroed in on men. However, the truth of the matter is that all kinds of people are similarly answerable for arranging and directing the family size. It is currently progressively perceived that the activities needed to accomplish enhancements in family arranging ought to likewise support the dynamic interest of men, subsequently investigating the job of spouse's prophylactic practices is especially significant. Male inclusion likewise incorporates the quantity of men who energize and support their accomplice and friends to utilize family arranging and who impact the approach climate to be more helpful for creating male - related projects. Thinking about the previously mentioned realities, the specialist felt that it is judicious to evaluate information and demeanor of men seeing family arranging strategies as no such review has been done in the comparable setting. Thus, the agent wanted to take up the review.

\section{Literature}

Review I: Review of the writing identified with adequacy of organized instructing program.

Review II: Audit of the writing identified with information on family arranging techniques.

\section{Conceptual Framework}




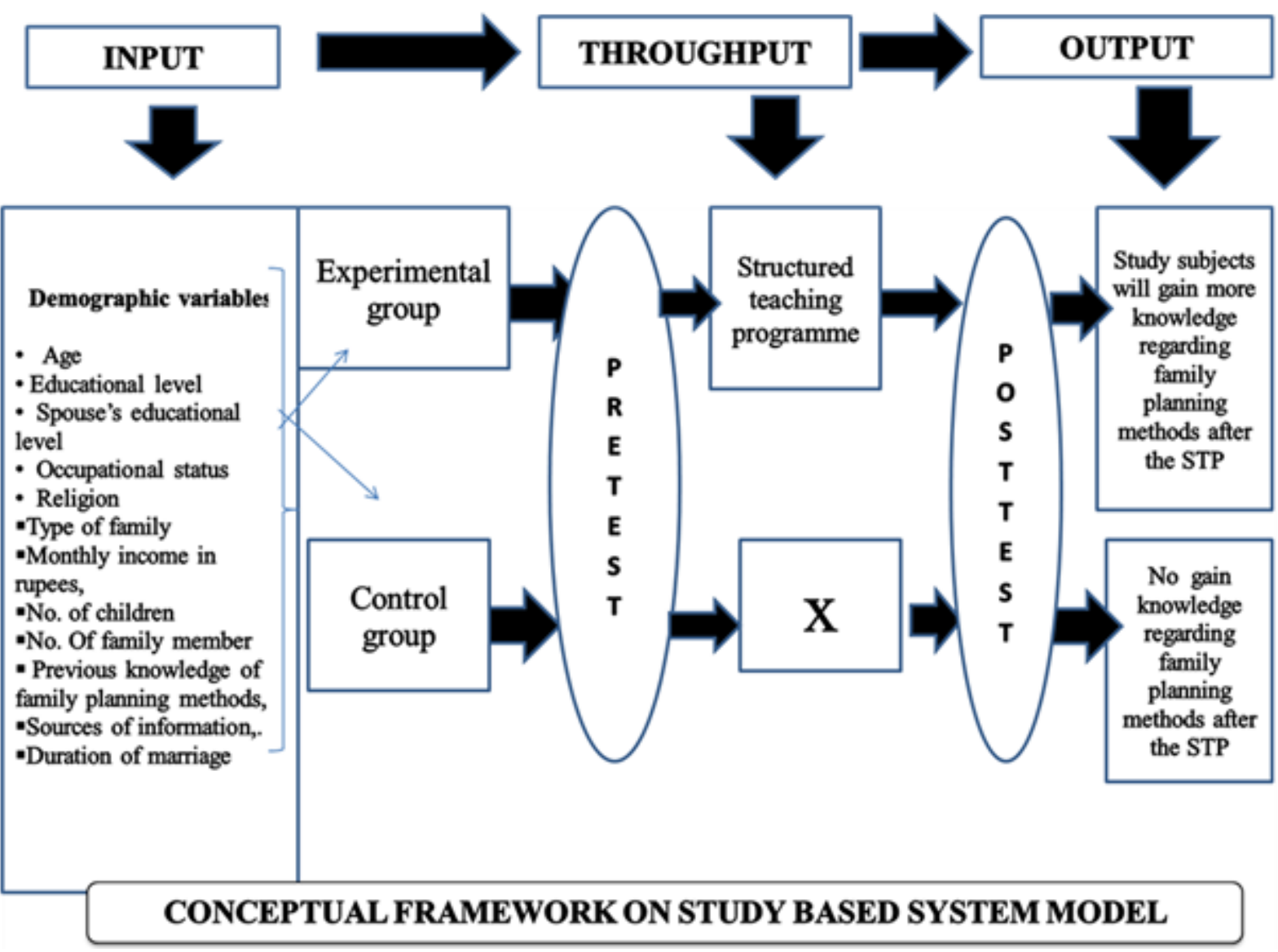

\section{Methodology}

This part manages the Research system embraced for the review. It incorporates the overall example for getting sorted out the strategy to gather legitimate and solid information for the issue under study. Exploration approach, research configuration, setting, test and inspecting strategy, advancement and portrayal of the device, populace, consideration avoidance rules, and content legitimacy and dependability of the apparatuses, pilot study and system for information assortment and plan for information investigation. Examination Approach The examination approach is the wide essential methodology for assortment information in a specific exploration circumstance. In quantitative examination, information assortment and investigation are created inside a logical way of thinking; it is utilized when the scientist wishes to gather data in a mathematical structure as the outcomes will be founded on meticulousness, objectivity and control. Quantitative methodology was chosen for the current review. Examination Design As indicated by Polit and Hunglar, The exploration configuration is the general arrangement, construction of examinations for getting replies to the inquiries being considered and testing the examination theory is alluded to as the exploration plan. In this review the agent chose semi exploratory, non - randomized benchmark group plan. Self - organized information Questionnaire apparatus unwavering quality was determined dependent on The Karl Pearson's recipe for test - re - test investigation of dependability for self - organized information poll after pilot testing was 0.80934 and this worth of Karl Pearson's test - re - test implies, the factors have a positive connection and it is adequate and this show that the survey utilized for the information assortment was solid.

\section{Result and Findings}

The aftereffect of the review introduced in this part dependent on the information gathered from subjects who were enlisted for evaluating the adequacy of organized showing program on information on family arranging techniques among men in chose provincial local area in Lucknow, U. P.

As indicated by Polit and Hungler (2010) information examination is the fundamental association and union of exploration speculation utilizing those information. In the review was examined utilizing graphic and inferential measurements dependent on the targets of the review and speculations to be tried. The destinations of the review were - To survey the pre - test level of information in regards to family arranging strategies among men of exploratory and control bunch. To survey the post - test level of information in regards to family arranging strategies among men of exploratory and control bunch. To survey the adequacy of construction showing program on information on family arranging strategies among men by looking at pre and post grade of control and exploratory gathering. To discover the relationship between chose demographical factors with the pre - test information in regards to family arranging strategies among men.

Section: 1 Examination of pre - test and post - test knowledge scores of men of age group between $21-50$ 
years of control and experimental respectively regarding selected family planning methods.

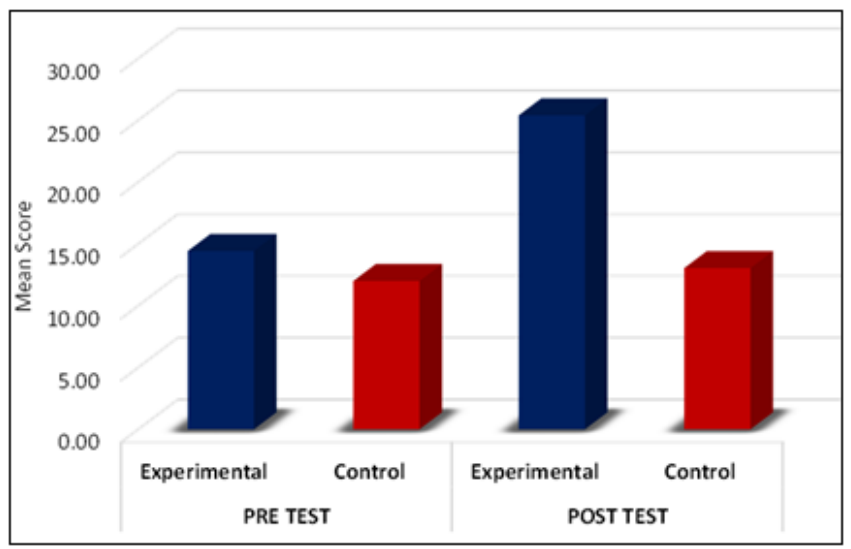

Figure 1: This figure represents the comparison of pre - test $\&$ post - test knowledge scores of control and experimental respectively

\section{Discussion}

In the experimental group most $(41.4 \%)$ respondent were in the age group 21 to 30 and in the control group most $(42.9 \%)$ were in age group 31 to 40 years.

In the experimental group most $(54.3 \%)$ respondent had primary education and in the control group most $(51.4 \%)$ were illiterate. In the experimental group most (65.7\%) respondents spouse were illiterate and in the control group most $(61.4 \%)$ respondents spouse were illiterate.

\section{Similar Study Finding}

Shabana Anjum, P. M Durgawali, Mhadeo Shinde (2013) conducted a study to assess the status of knowledge of contraception methods among married women's before and after health education, to correlate the selected demographic variable and status of knowledge regarding contraception method. Results shows that $99 \%$ users of condom, $86 \%$ skin implants, oral pills $85 \%$, emergency contraceptive users was $85 \%$ socio demographic variable was significantly associated with existing knowledge and level of married women's specially age at marriage, age of first child, occupation, income and education.

\section{References}

[1] Chand hick N, Dhillon BS, Kambo I, Saxena NC. Preventative information, practices and use of administrations in the country spaces of India. Indian $\mathbf{J}$ Med Sci [serial online] 2003 Jul [cited 2013 Nov15]; 57 (7): 303 - 10. Accessible from: http: //www.ncbi. nlm. nih. gov/pubmed/12928558

[2] Fehring RJ, Lawrence DM, Sauvage CM. Confidence, profound prosperity, and closeness: a correlation among couples utilizing NFP and oral contraceptives. Int Rev [serial online] 1989 [cited 2013 Nov 16]; 13 (3 - 4): 227 - 36. Accessible frohttp: //www.ncbi. nlm. nih. gov/pubmed/12179690

[3] Fehring RJ, Lawrence D, Philpot C. Use adequacy of the Creighton model ovulation technique for regular family arranging. J Obstet Gynecol Neonatal Nurs [serial online] 1994 May [cited 2013 Nov 20]; 23 (4): 303 - 9. Accessible from: URLhttp: //www.ncbi. nlm. nih. gov/pubmed/8057183

[4] Freundl G, Sivin I, Batár I. Best in class of non hormonal strategies for contraception: IV. Regular family arranging. Eur J Contracept Reprod Health Care [serial online] 2010 Apr [cited 2013 Nov 22]; 15 (2): 113 - 23. Accessible from: URL: http: //www.ncbi. nlm. nih. gov/pubmed/20141492

[5] Hughes J. Regular family arranging: extremely dangerous business. Soul [serial online] 1988Sep - Oct [cited 2013 Nov24]; 9 (5): 7 - 12. Accessible from: URL: http: //www.ncbi. nlm. nih. gov/pubmed/12178833

[6] Kumar S, Priyadarshini A, Kant S, Anand K, Yadhav B K, 2005, Attitude of ladies towards family arranging strategies and its utilization study from a ghetto of Delhi, Kathmandu University Medical Journal, Vol 3, No 3, Issue 11, 259 - 262.

[7] Suman Basu, Anoop Kumar and Salil Kumar Basu, 2004, Knowledge, demeanor and practice of family arranging among Tribas, Journal of Family Welfare, Vol 50, No 1: 24 - 27.

[8] Rao, Rama G, Moulasha K and Surender, 1993, Knowledge, demeanor and practice of family arranging among ladies of costal region in Tamil Nadu, The Journal of Family Welfare, 39 (3): 50 - 54. 